\title{
A Novel Chemical Pathway for Energy Efficient Production of Ti Metal from Upgraded
}

\section{Titanium Slag}

Ying Zhang\#, Z. Zak Fang*, Yang Xia, Zhe Huang, Hyrum Lefler, Tuoyang Zhang, Pei Sun, Michael L. Free and Jun Guo

Department of Metallurgical Engineering, the University of Utah, USA

*Corresponding author: zak.fang@utah.edu

${ }^{*}$ On leave from Institute of Process Engineering, Chinese Academy of Science (IPE, CAS)

\section{Abstract}

The developments of energy efficient, low cost titanium metal production processes have challenged the metallurgical industry and research community around the world for several decades. The strong affinity of titanium to oxygen dictates that the conventional Ti metal production processes are energy-intensive. In this paper, a new approach that is designed to minimize energy consumption and overall cost for Ti production is presented. The overall approach is based on a chemical pathway that synergistically integrating a series of low cost unit processes to produce Ti that can match the quality of the product produced by the Kroll process commercially to date. The key steps include production of purified $\mathrm{TiO}_{2}$ with controlled sizes and morphologies, Mg reduction in the presence of hydrogen to form porous $\mathrm{TiH}_{2}$, heat treatment to close the pores, and $\mathrm{Ca}$ de-oxygenation to reduce oxygen content to less than $0.15 w t \%$. The results show that this approach can indeed produce Ti metal powder that has high purity, low oxygen, and meets the specifications by ASTM for general purpose Ti sponge, directly from upgraded titanium slag (UGS) without the high temperature 
chlorination step.

Key words: titanium production, upgraded titanium slag, purified $\mathrm{TiO}_{2}, \mathrm{Mg}$ reduction, de-oxygenation 


\section{Introduction}

Titanium metal is a highly coveted material that has been widely used in aerospace, chemical processing, and biomedical industries. However, relative to its potential, Ti is highly underutilized due to the inherent high cost of production of Ti primary metal as well as its alloys, despite the fact that it is the ninth most abundant element and the fourth most abundant metal in the earth's crust [1].

Ti primary metal is primarily produced commercially using the Kroll process today. In the Kroll process, titanium tetrachloride $\left(\mathrm{TiCl}_{4}\right)$ is reduced by reacting it with liquid $\mathrm{Mg}$ to produce $\mathrm{Ti}$ metal. $\mathrm{TiCl}_{4}$ is a precursor produced by carbothermic reduction of $\mathrm{Ti}$ ore to produce Ti slag, followed by chlorination and purification. After the $\mathrm{Mg}$ reduction of $\mathrm{TiCl}_{4}$ at around $800 \sim 850{ }^{\circ} \mathrm{C}$, the reduction products containing $\mathrm{Ti}$ metal, $\mathrm{MgCl}_{2}, \mathrm{Mg}$ metal, and a small amount of $\mathrm{TiCl}_{3}$ and $\mathrm{TiCl}_{2}$, are refined by vacuum fractional distillation to remove impurities such as $\mathrm{MgCl}_{2}$ and $\mathrm{Mg}$, yielding purified Ti metal as the final product, which is typically called Ti sponge [2]. The main and arguably the only disadvantages of Kroll process is that it is energy intensive, slow, and expensive due to a number of specific technical reasons including the chlorination process and the high temperature vacuum distillation process to remove the byproduct of the reduction. Therefore, enormous research efforts have been made around the world in the last few decades to develop more energy efficient and lower cost processes.

There are two general approaches for Ti metal production: electrochemical methods and thermochemical methods. A typical example of the electrochemical approach is the FFC or 
Cambridge process [3] which relies on the reduction of titanium oxide through electrolysis. The Kroll process is an example of the thermochemical method. The research work of this article describes a new thermochemical method that consumes less energy and would thus be more cost effective than the Kroll process.

Thermochemical production of Ti involves the reduction of a precursor with a reductant. There are two main precursors: $\mathrm{TiCl}_{4}$ and $\mathrm{TiO}_{2}$. Using $\mathrm{TiCl}_{4}$ as the precursor to produce $\mathrm{Ti}$ metal has the advantage that $\mathrm{TiCl}_{4}$ can be extremely pure in its gaseous state, which logically enables the production of highly purified Ti metal. However, the purification processes to produce $\mathrm{TiCl}_{4}$, including the high temperature chlorination process from $\mathrm{TiO}_{2}$-bearing minerals involves a series of highly energy intensive and costly processes [4]. Motivated by the aim to avoid the high temperature chlorination process, there have been many investigations involving the use of commercial $\mathrm{TiO}_{2}[5,6]$, titania slag, synthetic rutile, or up-graded Ti slag ( $\sim 95 \%$ or higher $\mathrm{TiO}_{2}$ content) [7] as the precursor. Intuitively $\mathrm{TiO}_{2}$ would be a lower cost precursor than $\mathrm{TiCl}_{4}$ because the chlorination step could be avoided. However, the precursor is not the only factor that affects the cost of Ti. The differences in the inherent energies of reduction of either $\mathrm{TiO}_{2}$ or $\mathrm{TiCl}_{4}$, and the selection of reductants also affect the final cost of Ti metal.

Based on the Ellingham diagrams for metals' reaction with oxygen and chlorine, there are three possible reductants, namely $\mathrm{Mg}, \mathrm{Na}$ and $\mathrm{Ca}$, for reduction of either $\mathrm{TiO}_{2}$ or $\mathrm{TiCl}_{4}$. Figure 1 shows multiple potential thermochemical routes for production of Ti metal from the precursors using $\mathrm{Mg}, \mathrm{Na}$, and $\mathrm{Ca}$ as reductants.

Due to its extreme chemical affinity to $\mathrm{O}, \mathrm{Ca}$ metal, rather than $\mathrm{Mg}$, is frequently 
employed to reduce $\mathrm{TiO}_{2}$. Four different forms of $\mathrm{Ca}$ were investigated as options for calciothermic reduction, including solid hydride $\mathrm{CaH}_{2}$ [8], vapor-Ca [9], liquid-Ca [10], and electronically mediated reduction (EMR) [11]. The oxygen content in Ti can be minimized to a very low level using Ca.

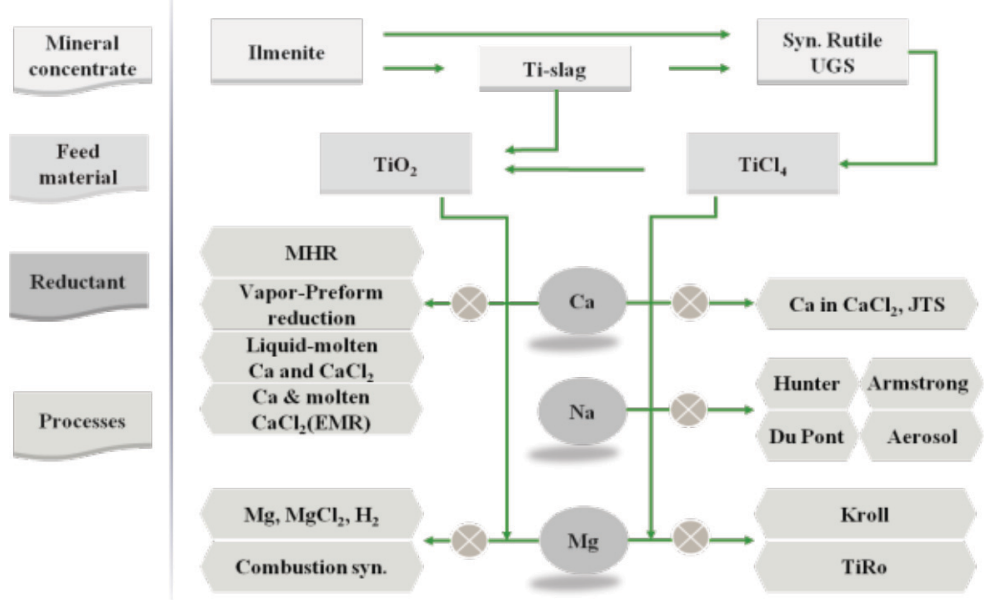

Fig. 1 Thermochemical reduction routes to produce Ti metal through various reductants

Compared to $\mathrm{Ca}, \mathrm{Na}$ is chemically inert to $\mathrm{TiO}_{2}$. It is, however, an effective reductant for reducing $\mathrm{TiCl}_{4}$. The power of reduction of $\mathrm{Na}$ is equivalent to that of $\mathrm{Ca}$, and both are significantly stronger than that of $\mathrm{Mg}$, which led to the development of a variety of processes based on $\mathrm{Na}$ reduction of $\mathrm{TiCl}_{4}$, including the Hunter process [12], the Armstrong process [13], Du Pont [14], and Aerosol methods [15].

Although $\mathrm{Mg}$ is not as strong as $\mathrm{Ca}$ or $\mathrm{Na}$ for reduction purposes, it is still effective for reduction of both $\mathrm{TiO}_{2}$ and $\mathrm{TiCl}_{4} . \mathrm{Mg}$ has, of course, been used in the Kroll process for reduction of $\mathrm{TiCl}_{4}$. Based on a process energy analysis of the Kroll process reported by Rajiv Kohli [16], almost $2 / 3$ of the total energy for production of Ti using the Kroll process is consumed by the high-temperature vacuum distillation and separation following the actual 
reduction process, and $13 \%$ is consumed by the chlorination and purification processes. Thus, it is logical to suggest that a process designed to reduce $\mathrm{TiO}_{2}$ using $\mathrm{Mg}$ could be more energy efficient and less expensive than the Kroll process because there will be no need for high temperature vacuum distillation of the byproduct of $\mathrm{MgO}$; and $\mathrm{Mg}$ is also the least expensive reductant among $\mathrm{Mg}, \mathrm{Ca}$, and $\mathrm{Na}$. The byproduct of the reduction of $\mathrm{TiO}_{2}$ by $\mathrm{Mg}$ is $\mathrm{MgO}$ that must be removed using aqueous leaching techniques. The energy consumption and cost of such processes for removing the by-products of the reduction will also impact the final cost.

Recently, a new process was proposed by Fang et al. that produces $\mathrm{Ti}$ by direct reduction of upgraded Ti slag (UGS) using Mg under a hydrogen atmosphere [17]. A key consideration of the Fang approach is that it starts with a low cost precursor (UGS) and it employs the least expensive reductant $(\mathrm{Mg})$. An advantage of the Fang approach is that it forms $\mathrm{TiH}_{2}$ after the reduction which separates $\mathrm{Ti}$ chemically from other impurities, thereby facilitating impurity removal by chemical leaching. $\mathrm{TiH}_{2}$ is known to be impervious to oxygen and less prone to alloying with the impurity elements in the mixture. However, removing impurities, i.e. the purification process is challenging because $\mathrm{TiH}_{2}$ is prone to dissolution along with the impurities during the post-reduction leaching process. The process of purification is therefore another important factor, in addition to the cost of precursor and reductant.

In short, the energy consumption and cost of Ti metal production from Ti slag depend on several key factors, including the selection of precursor and reductant, the processes for purification, the processes for removing byproducts, and the processes for reclaiming the reductant and other chemical reagents. In this paper, a new chemical pathway is designed to 
produce pure Ti from UGS without the energy intensive high temperature chlorination step and without the post-reduction high temperature vacuum distillation step as in the Kroll process. The new chemical pathway integrates a series of low cost purification and reduction processes synergistically to produce Ti with high purity and low oxygen. The aim of this paper is to present the concept and the design of the overall process, and report experimental results of key intermediate steps. The results show that highly purified Ti metal with low oxygen content can be achieved using this new approach.

\section{Process design concept}

The new process design is shown in Fig. 2. First of all, UGS is selected as the starting raw material. The first part of the overall process is to produce purified titanium dioxide $\left(\mathrm{TiO}_{2}\right)$ using hydrometallurgical method. The second step is to reduce the purified $\mathrm{TiO}_{2}$ using $\mathrm{Mg}$ in a hydrogen atmosphere. The last step involves the deoxygenation that is specifically designed to remove oxygen that is dissolved in Ti metal.

\subsection{Produce purified $\mathrm{TiO}_{2}$}

The first step of the overall process is the thermal alkaline roasting of UGS with $\mathrm{NaOH}$ and subsequent washing with water. There are two objectives for alkaline roasting. One is to transform all metal components into sodium metallate, especially amorphous sodium titanate, which is insoluble in water, but can be readily dissolved in dilute $\mathrm{HCl}$ acid solution. The titanic acid will subsequently be selectively precipitated and calcined to produce $\mathrm{TiO}_{2}$. The second objective of alkaline roasting is to leach most of the impurities including $\mathrm{Si}, \mathrm{Al}, \mathrm{Cr}$ and $\mathrm{V}$ by forming their sodium metallate that are soluble in water and alkaline solutions. The 
washed alkaline roasted product will be solid $\mathrm{H}_{2} \mathrm{TiO}_{3}$ with significantly reduced impurities compared to UGS.

Transition metals such as iron (Fe) and $\mathrm{Ti}$, however, do not dissolve in water or the alkaline solution. Thus the next step of the process is designed to dissolve Fe along with titanate $\left(\mathrm{TiO}_{3}{ }^{2-}\right)$ in a dilute $\mathrm{HCl}$ solution. Hydrolysis is then instigated to selectively precipitate titanic acid and separate Ti from other impurities. Note Fe does not co-precipitate with Ti and thus it is left in the solution. Additionally, the hydrolysis process is not only a purification technique, but it is also a process that can be used to control particle size and morphology of the product powder. The particle size, size distributions, and morphology depend strongly on the concentration of $\mathrm{HCl}$ in the solution, the temperature, time, and agitation of the solution. In order to minimize oxygen content in the final powder, the hydrolysis process parameters are adjusted to produce relatively coarse titanic acid particles (5-50 micrometers). The titanic acid particles are then calcined to transform into relatively coarse $\mathrm{TiO}_{2}$. Note that although commercial $\mathrm{TiO}_{2}$ is readily available as pigment grade $\mathrm{TiO}_{2}$, commercial $\mathrm{TiO}_{2}$ is not chosen for direct $\mathrm{Mg}$ reduction because the particle size of pigment grade $\mathrm{TiO}_{2}$, typically $200-300 \mathrm{~nm}$, is too fine for controlling oxygen content during the subsequent processing steps. The differences between the purified $\mathrm{TiO}_{2}$ of this work and the commercial pigment grade $\mathrm{TiO}_{2}$ will be further discussed later.

\subsection{Reduction of $\mathrm{TiO}_{2}$}

The second part of the overall process is to reduce the purified $\mathrm{TiO}_{2}$ to Ti metal. $\mathrm{Mg}$ is selected as the reductant. The reduction process is designed to be conducted in a hydrogen atmosphere in order to form $\mathrm{Ti}$ hydride $\left(\mathrm{TiH}_{2}\right)$ rather than $\mathrm{Ti}$ metal. An important advantage 
of forming $\mathrm{TiH}_{2}$ rather than $\mathrm{Ti}$ is that $\mathrm{TiH}_{2}$ is impervious to oxidation in air. It is also believed that $\mathrm{TiH}_{2}$ is less prone to alloying with other impurities than Ti metal.

After $\mathrm{Mg}$ reduction in $\mathrm{H}_{2}$, the byproduct of $\mathrm{MgO}$ and unreacted $\mathrm{Mg}$ metal are leached using aqueous $\mathrm{HCl}$ solution. The acidity of the slurry during leaching must be carefully controlled to avoid the dissolution of $\mathrm{TiH}_{2}$.

After the reduction and subsequent leaching, $\mathrm{TiH}_{2}$ powder is obtained. A heat treatment step is incorporated to reduce the surface area and obtain dense particles. Increasing particle size or minimizing specific surface area is beneficial for minimizing oxygen pick up during subsequent handling of the powder. During the heat treatment, the $\mathrm{TiH}_{2}$ powder will also be dehydrogenated.

\subsection{Deoxygenation}

Commercial specifications require the oxygen content of Ti sponge to be less than $0.15 \%$. The oxygen content of $\mathrm{Mg}$ reduced $\mathrm{TiO}_{2}$ is expected to be greater than $1 \%$ [18]. Therefore, a de-oxygenation process is necessary and integrated as a part of the overall process. De-oxygenation can be carried out by mixing the powder with $\mathrm{Ca}$ metal and heating the mixture to elevated temperatures to reduce its oxygen content according to existing processes as reported in literature [19-21]. In this work a low temperature molten salt (LTMS) process was applied by which the deoxygenation process is designed to operate at temperatures lower than the melting point of $\mathrm{Ca}$. Molten $\mathrm{CaCl}_{2}$ is used as a medium to facilitate the reaction. Details of the LTMS process can be found in reference [22]. The by-product of the de-oxygenation process will be $\mathrm{CaO}$ which can also be leached using a dilute $\mathrm{HCl}$ solution.

In short, the process for production of Ti metal from UGS involves making purified 
$\mathrm{TiO}_{2}$, the reduction of purified $\mathrm{TiO}_{2}$ by $\mathrm{Mg}$ in hydrogen, and de-oxygenation using Ca. Both the concept of the overall chemical pathway and the details of the individual techniques are designed to work synergistically to accomplish the tasks of both purification and reduction of titanium oxide to produce Ti metal. Details of each processing step and the effectiveness of the entire process are further illustrated through the experimental results and discussions as follows.

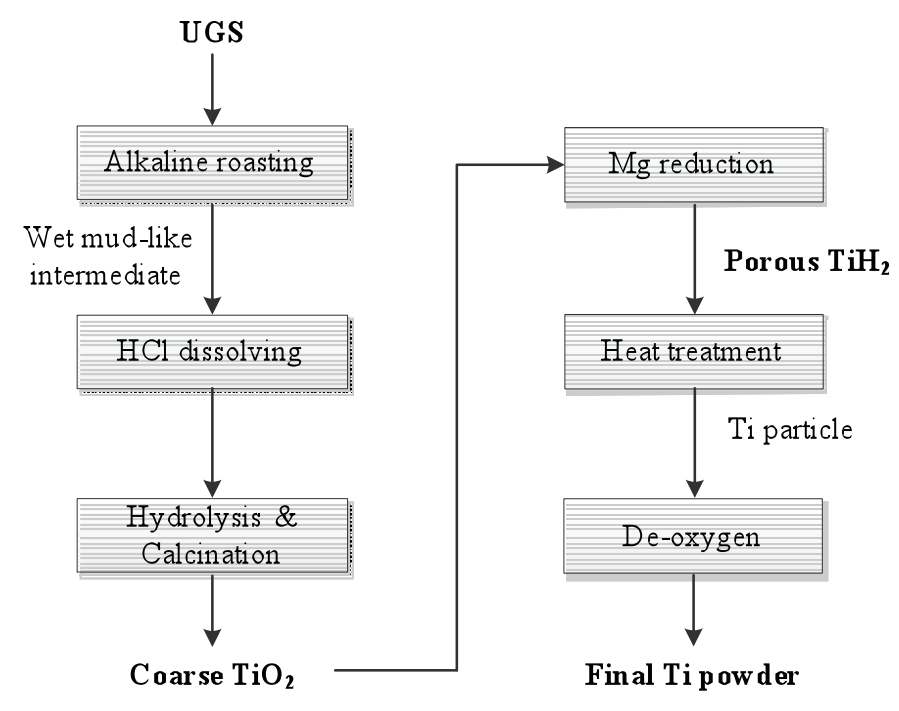

Fig. 2 Flow chart of the new approach for Ti powder production

\section{Experimental}

\subsection{Procurement of raw materials and chemicals}

Up-graded Ti-slag (UGS), assaying 94.5\% $\mathrm{TiO}_{2}$, was provided by Rio Tinto and used as the raw material in this work. The chemical composition of UGS is given in Table 1, which shows that the impurity contents including $\mathrm{Fe}, \mathrm{Si}, \mathrm{Mg}$ and $\mathrm{Al}$ were all relatively high. UGS is commercially used as the feedstock for the chloride process of making $\mathrm{TiO}_{2}$ pigment. The particle size of as-received UGS is in the range of several hundred microns. Thus, it was wet milled and screened to minus 20 microns before alkaline roasting. 
Table 1 Chemical composition of original UGS (wt\%)

\begin{tabular}{cccccccccc}
\hline $\mathrm{Ti}$ & $\mathrm{O}$ & $\mathrm{Fe}$ & $\mathrm{Mg}$ & $\mathrm{Al}$ & $\mathrm{Ca}$ & $\mathrm{Si}$ & $\mathrm{Cr}$ & $\mathrm{Mn}$ & $\mathrm{V}$ \\
\hline 56.7 & 40.4 & 1.0 & 0.42 & 0.26 & 0.09 & 0.84 & 0.05 & 0.03 & 0.22 \\
\hline
\end{tabular}

Other chemicals involved in this study include $\mathrm{NaOH}$, concentrated $\mathrm{HCl}$ solution, $\mathrm{Mg}$ metal, $\mathrm{MgH}_{2}$ powder, $\mathrm{Ca}$ metal, anhydrous $\mathrm{MgCl}_{2}, \mathrm{CaCl}_{2}, \mathrm{KCl}$, and compressed hydrogen and argon. $\mathrm{Mg}$ and anhydrous salts were purchased from Alfa Aesar and preserved in an glove box with constant circulation of Ar to avoid oxidation and absorption of moisture. Water is purified with Milli-Q (Millipore Corp.) equipment before use. Standard solutions for ICP-OES test are purchased from Inorganic Ventures.

\subsection{Analytical methods, measurement of physical and chemical properties}

Through the whole process, the chemical compositions and interstitial element contents of the solid and liquid intermediates and final product were monitored. Solid samples were totally dissolved by $6 \mathrm{~mol} / \mathrm{L} \mathrm{HCl}$ solution after being fused by the mixture of sodium carbonate and boric acid in a Pt crucible, then the solutions were analyzed using ICP-OES. The concentrations in the liquid samples were directly determined by using ICP-OES after being diluted. The contents of $\mathrm{O}, \mathrm{N}, \mathrm{H}, \mathrm{C}$ interstitial elements were determined by using LECO analyzers.

A Philips 1140 diffractometer $(\mathrm{Cu} \mathrm{K} \alpha)$ X-Ray diffraction (XRD) unit, was used to determine the phase compositions of the precursor, intermediates, and final products. The 
morphologies and the particle size of the solid samples were examined using a scanning electron microscope (SEM, FEI NovaNano 630). Particle size and size distributions were determined using a Shimadzu particle size analyzer. The specific surface area was evaluated by using a BET analyzer (TriStar II). The density of the powder was measured using AccuPyc II 1340 Series Pycnometers.

\section{Results and Discussion}

\subsection{Production of purified $\mathrm{TiO}_{2}$ from UGS}

\subsubsection{Alkaline roasting}

As described earlier, alkaline roasting is the first step of the process to produce purified $\mathrm{TiO}_{2}$. The impurities in UGS can be classified into two categories, alkali-soluble impurities including $\mathrm{Si}, \mathrm{Al}, \mathrm{V}, \mathrm{Mn}$ and $\mathrm{Cr}$, and acid-soluble impurities including $\mathrm{Fe}, \mathrm{Al}, \mathrm{V}, \mathrm{Ca}, \mathrm{Mg}, \mathrm{Si}$, $\mathrm{Mn}$ and $\mathrm{Cr}$. However, except for Si, most of the impurities in UGS do not exist as stand-alone phases; rather, they form solid solutions with $\mathrm{TiO}_{2}$ in the form of rutile. The reported empirical formulas for the core and the rim of the rutile grains are $\mathrm{Ti}_{0.896} \mathrm{Fe}_{0.045} \mathrm{Mg}_{0.089} \mathrm{Al}_{0.024} \mathrm{~V}_{0.006} \mathrm{Cr}_{0.002} \mathrm{Mn}_{0.002} \mathrm{O}_{2}$ and $\mathrm{Ti}_{0.993} \mathrm{Fe}_{0.003} \mathrm{~V}_{0.005} \mathrm{Cr}_{0.001} \mathrm{O}_{2}$, respectively [23]. In other words, some impurities such as $\mathrm{Fe}, \mathrm{Mg}, \mathrm{Al}$, and $\mathrm{V}$, are hosted within the lattice of rutile. With regard to $\mathrm{Si}$, it exists as a glassy silicate phase and fills the cracks between rutile grains [23]. Based on the above, it is plausible to leach the impurities by destroying the structure and chemically separating them from the titanium dioxide. Other procedures were also applied in addition to alkaline roasting to minimize Si content.

With the aim to digest the titanium feed stocks, including ilmenite, titania slag or 
upgraded titania slag, typical hydrometallurgical methods, such as the sulfate process [24], use highly concentrated sulfuric acid to dissolve titanium and all impurities into solution. Concentrated $\mathrm{HCl}$ may also be used [25]. To avoid using concentrated acid, the process of pretreating the feedstock with an alkaline roasting step by $\mathrm{NaOH}$, followed by dissolving the material in a low-concentration acid [26] was selected for this work. The principle of $\mathrm{NaOH}$ roasting is as follows. On the one hand, titanium dioxide and alkali-soluble impurities can be transformed during roasting into their sodium metallate salts, mainly $\mathrm{Na}_{2} \mathrm{TiO}_{3}$ accompanied by $\mathrm{Na}_{2} \mathrm{SiO}_{3}, \mathrm{NaAlO}_{2}, \mathrm{Na}_{3} \mathrm{VO}_{4}, \mathrm{Na}_{2} \mathrm{CrO}_{4}, \mathrm{Na}_{3} \mathrm{MnO}_{4}$. On the other hand, alkali-insoluble impurities can also be hosted by their sodium metallate salts or metal hydroxide compounds, such as $\mathrm{NaFeO}_{2}$ [27], $\mathrm{Na}_{2} \mathrm{MgO}_{2}$ [28] and $\mathrm{Ca}(\mathrm{OH})_{2}$. After roasting, the reaction product can be washed using water during which the excess $\mathrm{NaOH}$ will be dissolved, and most of the sodium combined with $\mathrm{Na}_{2} \mathrm{TiO}_{3}$ will be released to form water-soluble $\mathrm{NaOH}$ and alkali-insoluble metatitanic acid $\left(\mathrm{H}_{2} \mathrm{TiO}_{3}\right)$. Additionally, the alkali-insoluble metals will be retained with metatitanic acid in their metal hydroxide compounds of $\mathrm{Fe}(\mathrm{OH})_{3}, \mathrm{Mg}(\mathrm{OH})_{2}$ and $\mathrm{Ca}(\mathrm{OH})_{2}$. The reactions involved in this process are listed as Eq. (1) to Eq. (8). Thus, the goal of chemically separating titanium and other impurities is achieved.

Alkaline roasting:

$$
\begin{aligned}
& \mathrm{Ti}_{0.896} \mathrm{Fe}_{0.045} \mathrm{Mg}_{0.089} \mathrm{Al}_{0.024} \mathrm{~V}_{0.006} \mathrm{Cr}_{0.002} \mathrm{Mn}_{0.002} \mathrm{O}_{2}+2.067 \mathrm{NaOH}+0.00525 \mathrm{O}_{2} \\
& =0.896 \mathrm{Na}_{2} \mathrm{TiO}_{3}+0.024 \mathrm{NaAlO}_{2}+0.006 \mathrm{Na}_{3} \mathrm{VO}_{4}+0.002 \mathrm{Na}_{2} \mathrm{CrO}_{4} \\
& +0.002 \mathrm{Na}_{3} \mathrm{MnO}_{4}+0.045 \mathrm{NaFeO}_{2}+0.089 \mathrm{Na}_{2} \mathrm{MgO}_{2}+1.0335 \mathrm{H}_{2} \mathrm{O} \\
& \mathrm{Ti}_{0.993} \mathrm{Fe}_{0.003} \mathrm{~V}_{0.005} \mathrm{Cr}_{0.001} \mathrm{O}_{2}+2.006 \mathrm{NaOH}+0.003 \mathrm{O}_{2}=0.993 \mathrm{Na}_{2} \mathrm{TiO}_{3} \\
& +0.005 \mathrm{Na}_{3} \mathrm{VO}_{4}+0.001 \mathrm{Na}_{2} \mathrm{CrO}_{4}+0.003 \mathrm{NaFeO}_{2}+1.003 \mathrm{H}_{2} \mathrm{O} \\
& 2 \mathrm{NaOH}+\mathrm{TiO}_{2}=\mathrm{Na}_{2} \mathrm{TiO}_{3}+\mathrm{H}_{2} \mathrm{O} \\
& 2 \mathrm{NaOH}+\mathrm{SiO}_{2}=\mathrm{Na}_{2} \mathrm{SiO}_{3}+\mathrm{H}_{2} \mathrm{O}
\end{aligned}
$$




$$
2 \mathrm{NaOH}+\mathrm{Al}_{2} \mathrm{O}_{3}=2 \mathrm{NaAlO}_{2}+\mathrm{H}_{2} \mathrm{O}
$$

Water washing:

$$
\begin{aligned}
& \mathrm{Na}_{2} \mathrm{TiO}_{3}+\mathrm{H}_{2} \mathrm{O}=\mathrm{H}_{2} \mathrm{TiO}_{3}+2 \mathrm{NaOH} \\
& \mathrm{NaFeO}_{2}+2 \mathrm{H}_{2} \mathrm{O}=\mathrm{Fe}(\mathrm{OH})_{3}+\mathrm{NaOH} \\
& \mathrm{Na}_{2} \mathrm{MgO}_{2}+2 \mathrm{H}_{2} \mathrm{O}=\mathrm{Mg}(\mathrm{OH})_{2}+2 \mathrm{NaOH}
\end{aligned}
$$

Experimental investigation of the $\mathrm{NaOH}$ roasting process was conducted at $500{ }^{\circ} \mathrm{C}$ for 1 hour with a mass ratio of $\mathrm{NaOH}$ to UGS of $1.5: 1$. The parameters of the roasting process were determined based on the present authors' prior research [26] as well as published reports by their research peers [29]. The phase composition of the dried water-washed residue is shown in Fig 13 (B). Figure 13 shows that the UGS with XRD pattern in Fig. 13 (A) was completely transformed during roasting without any leftover rutile. The chemical composition of the residue was analyzed using ICP and the results are shown in Table 2 . Based on the composition it is deduced that the residue is primarily composed of $\mathrm{H}_{2} \mathrm{TiO}_{3}$. The effectiveness of the alkaline roasting process in terms of the removal rates of the impurities were calculated and they are as high as $97.5 \%, 94.5 \%, 88.8 \%, 83.0 \%$ and $78.8 \%$, for $\mathrm{Si}, \mathrm{Al}$, $\mathrm{V}, \mathrm{Mn}$ and Cr respectively. Even Fe and $\mathrm{Mg}$ were partially dissolved by the alkaline solution, which may be attributed to their limited but detectable solubility in the alkaline solution.

It should be noted that oxidation is a necessary step during roasting because some of the impurities including $\mathrm{V}, \mathrm{Mn}$ and $\mathrm{Cr}$ in the original UGS are in their reduced states of $\mathrm{V}^{4+}$, $\mathrm{Mn}^{2+}$ and $\mathrm{Cr}^{3+}$, while only their sodium salts with high valence could be readily dissolved in the alkaline solution. This is attributed to the processes that produce UGS which include oxidation, reduction, and high pressure $\mathrm{HCl}$ leaching. Thus, the roasting was conducted in air. 
Table 2 Chemical composition of the dried residue and the impurity removal rates

\begin{tabular}{cccccccccc}
\hline Element & $\mathrm{Ti}$ & $\mathrm{Fe}$ & $\mathrm{Mg}$ & $\mathrm{Al}$ & $\mathrm{Ca}$ & $\mathrm{Si}$ & $\mathrm{Cr}$ & $\mathrm{Mn}$ & $\mathrm{V}$ \\
\hline$w t \%$ & 40.00 & 0.483 & 0.156 & 0.010 & 0.072 & 0.038 & 0.008 & 0.004 & 0.017 \\
\hline Removal rate & & & & & & & & & \\
$(\%)$ & 0 & 31.5 & 47.3 & 94.5 & 0 & 97.5 & 78.8 & 83.0 & 88.8 \\
\hline
\end{tabular}

\subsubsection{Dissolution}

After the roasting process described above, the transition metal species such as Fe are still in the residue of water-washed alkaline roasted product, which is a mud-like intermediate (referred to as "mud" hereafter). These impurities have to be further separated from metatitanic acid. The only plausible pathway to achieve that is through total dissolution of the mud and re-precipitation of titanium dioxide from the Ti-bearing acid solution. As the result of the alkaline roasting, the chemically stable rutile in the original UGS has been transformed into extremely active metatitanic acid, which can be readily dissolved in diluted acid solutions $\left(\mathrm{HCl}\right.$ or $\left.\mathrm{H}_{2} \mathrm{SO}_{4}\right)$ at a low temperature. In this research, the wet mud, containing $50 \%$ water mass content, was immersed in $\mathrm{HCl}$ solution to dissolve it. The initial $\mathrm{HCl}$ concentration of the solution was $6 \mathrm{~mol} / \mathrm{L}$ and the experiment was conducted at $50{ }^{\circ} \mathrm{C}$ for 30-60 minutes [30]. The total amount of $\mathrm{HCl}$ used is based on the total mass of $\mathrm{Ti}$ in the wet mud. It should be noted that the water in the wet mud was taken into account for determining the concentration of $\mathrm{HCl}$ solution.

After the dissolution, the leachate was filtered to remove insoluble particles and a 
transparent Ti-bearing solution was obtained in preparation for the hydrolysis step.

The typical composition of the solution before hydrolysis is shown in Table 3 .

Table 3 Main metal concentrations in the $\mathrm{HCl}$ leachate $(\mathrm{mg} / \mathrm{L})$

\begin{tabular}{ccccccccc}
\hline $\mathrm{Ti}$ & $\mathrm{Mg}$ & $\mathrm{Al}$ & $\mathrm{Fe}$ & $\mathrm{Si}$ & $\mathrm{Ca}$ & $\mathrm{Cr}$ & $\mathrm{V}$ & $\mathrm{Mn}$ \\
\hline 49000 & 222 & 7 & 664 & 18 & 45 & 7 & 19 & 4 \\
\hline
\end{tabular}

The reason for $6 \mathrm{~mol} / \mathrm{L} \mathrm{HCl}$ of the leaching medium is based on the following considerations: (1) Over exorbitant lixiviant, such as concentrated $\mathrm{HCl}$, will make the handling more difficult and the lack of water molecules has an adverse effect on dissolution; (2) Ti ions are not stable in weak acid solution and the generation of water during dissolution will further dilute the acid, which could create a risk of premature hydrolysis. The free $\mathrm{HCl}$ concentration in the leachate after the present dissolution was still as high as around $2 \mathrm{~mol} / \mathrm{L}$; (3) Even though it has been shown that $4 \mathrm{~mol} / \mathrm{L} \mathrm{HCl}$ also works for the purpose of this work [31], the lower the $\mathrm{HCl}$ concentration, the lower the $\mathrm{Ti}$ concentration and corresponding hydrolysis ratio. Thus, $6 \mathrm{~mol} / \mathrm{L} \mathrm{HCl}$ was determined to be the optimum concentration.

\subsubsection{Hydrolysis and calcination}

Hydrolysis is a process of selective and spontaneous precipitation of Ti species from the Ti-bearing acid solution in the form of titanic acid. Various titanic acids with a general formula of $\mathrm{TiO}_{x}(\mathrm{OH})_{4-2 x}$ depending on the water content in them can be obtained by controlling hydrolysis parameters. The general chemical reaction involved is shown as Eq. 
(9). The product of hydrolysis can be metatitanic acid $\left(\mathrm{TiO}(\mathrm{OH})_{2}\right)$, orthotitanic acid $\left(\mathrm{Ti}(\mathrm{OH})_{4}\right)$, or pyrotitanic acid $\left(\mathrm{H}_{2} \mathrm{Ti}_{2} \mathrm{O}_{5}\right)$, and so forth.

$$
\mathrm{Ti}^{4+}+(4-x) \mathrm{H}_{2} \mathrm{O}=\mathrm{TiO}_{x}(\mathrm{OH})_{4-2 x}+4 \mathrm{H}^{+}
$$

In this study, the liquid after dissolution of wet mud is a $\mathrm{TiCl}_{4}$-bearing solution. In this solution, an equivalent concentration of $\mathrm{TiO}_{2}$ based on the concentration of $\mathrm{Ti}^{4+}$ was controlled to be around $80 \mathrm{~g} / \mathrm{L}$. The hydrolysis was carried out at $95-100{ }^{\circ} \mathrm{C}$ for 16 hours. The solution was continuously stirred.

The product of hydrolysis was solid titanic acid particles, with particle sizes ranging from approximately 10 to 50 microns using the above parameters. The morphology and particle size distribution are shown in Fig. 3 and Fig. 4. Particles are mostly aggregates of fine crystals.
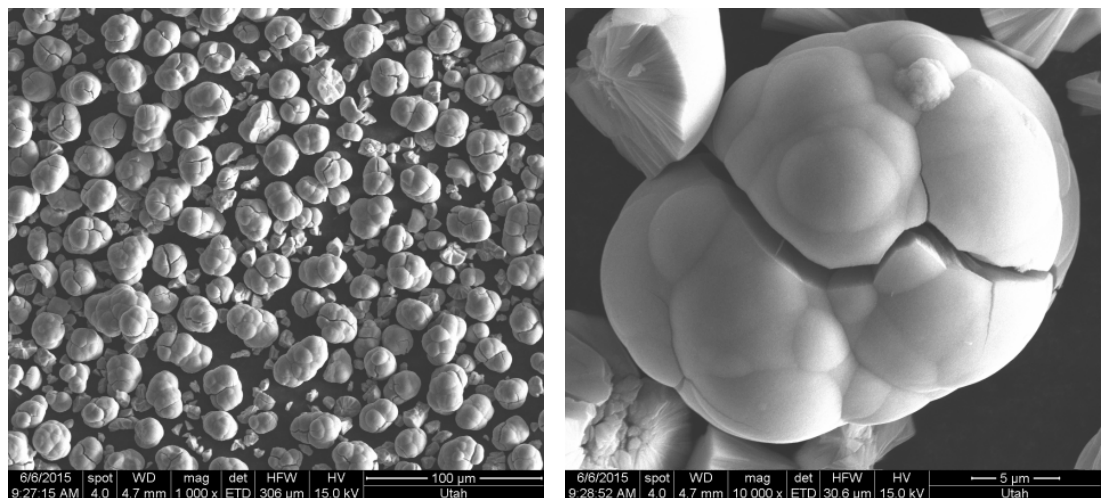

Fig. 3 Morphology of the hydrolyzed titanic acid particles 


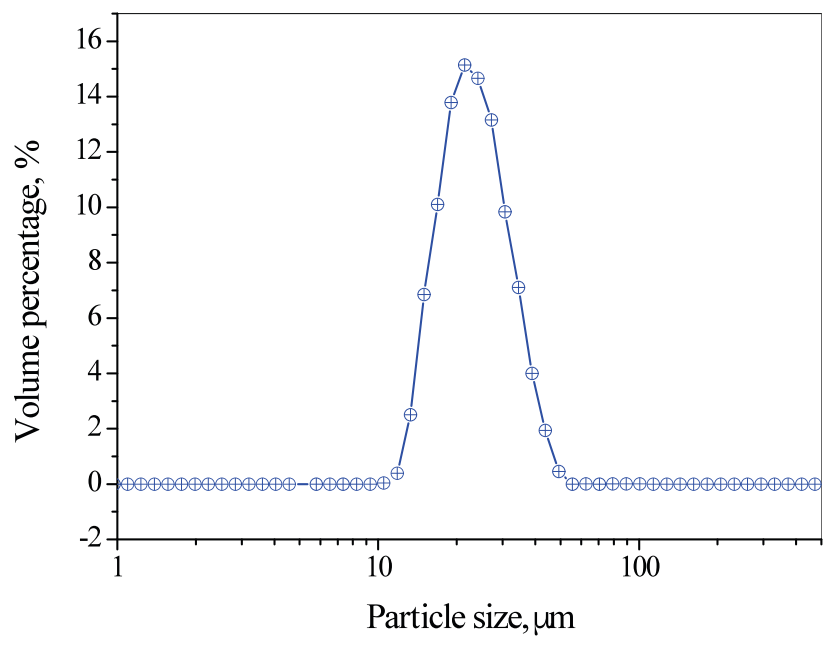

Fig. 4 Particle size distribution of the hydrolyzed titanic acid particles

After the hydrolysis, the titanic acid precipitate was subjected to calcination by heating up gradually to dehydrate the precipitate particles and to obtain rutile at $900{ }^{\circ} \mathrm{C}$ in air. Rutile is the high-temperature stable phase that is easier to reduce than Anatase [32]. The XRD pattern of the post-calcination particles is shown in Fig. 13 (C). According to the weight loss during calcination, it was confirmed that the water content in the precipitate was approximately $10 \%$, suggesting that the precipitate was pyrotitanic acid. The morphology of rutile particles inherits that of the titanic acid. And the purity of rutile, or impurity contents in the material were analyzed by using ICP and the results are shown in Table 4, which is also compared with commercial rutile. It is apparent that the purity of $\mathrm{TiO}_{2}$ produced by this process is comparable to that of commercial rutile.

Table 4 Comparison of the impurity contents in rutile prepared by this work and in commercial pigment grade rutile [31], wt $\%$

$\begin{array}{llllllllll}\mathrm{Mg} & \mathrm{Al} & \mathrm{Fe} & \mathrm{Si} & \mathrm{Ca} & \mathrm{Cr} & \mathrm{V} & \mathrm{Mn} & \mathrm{C}\end{array}$




\begin{tabular}{cccccccccc}
\hline This work & 0.048 & 0.006 & 0.043 & 0.030 & 0.029 & 0.018 & 0.037 & 0.005 & 0.0035 \\
\hline Commercial & 0.030 & NA & 0.0012 & 0.0386 & 0.0112 & $<0.0013$ & NA & $<0.0007$ & NA \\
\hline
\end{tabular}

There are two critical issues during hydrolysis: purifying the material, especially the removal of iron, and controlling size and morphology of the particles. The purity of $\mathrm{TiO}_{2}$ has a direct impact on the purity of Ti metal in the end. In this study, the ferric ion in the pre-hydrolysis solution was reduced by $\mathrm{Ti}^{3+}$ ion to ferrous ion. During the precipitation of titanic acid, ferrous ion will remain in the leaching solution, thus separating $\mathrm{Fe}$ from $\mathrm{Ti}$, thereby minimizing iron content in $\mathrm{TiO}_{2}$. Table 5 compares the $\mathrm{Fe}$ content as well as other compositions before and after the hydrolysis. Clearly the Fe content is significantly and sufficiently minimized in $\mathrm{TiO}_{2}$.

Table 5 Chemical composition comparison of the solution before and after hydrolysis $(\mathrm{mg} / \mathrm{L})$

\begin{tabular}{cccccccccc}
\hline & $\mathrm{Ti}$ & $\mathrm{Mg}$ & $\mathrm{Al}$ & $\mathrm{Fe}$ & $\mathrm{Si}$ & $\mathrm{Ca}$ & $\mathrm{Cr}$ & $\mathrm{V}$ & $\mathrm{Mn}$ \\
\hline Pre-hydrolysis & 49000 & 222 & 7 & 664 & 18 & 45 & 7 & 19 & 4 \\
Post-hydrolysis & 880 & 231 & 8 & 690 & 4 & 52 & 5 & 4 & 5 \\
\hline
\end{tabular}

Theoretically, commercial pigment grade $\mathrm{TiO}_{2}$ could be used as a raw material for making Ti metal according to the process of this paper. However, there are several reasons that it is believed to be more advantageous to prepare $\mathrm{TiO}_{2}$ according to the process described above.

First, commercial $\mathrm{TiO}_{2}$ that are currently available in large quantities are almost all 
exclusive produced for $\mathrm{TiO}_{2}$ pigment, which have particle sizes in the range of 200-300 nm in diameter [33], which the most efficient size for scattering yellow-green light that the human eyes are most sensitive to [34]. This particle size is too fine to be used directly in the $\mathrm{Mg}$ reduction process of this work for the purpose of producing Ti metal, because the reduced product $\left(\mathrm{TiH}_{2}\right.$ in this process) will be prone to oxidation as soon as it is exposed to air.

Second, the oxygen content of Ti metal powder is a direct function of the particle size due to the formation of $\mathrm{TiO}_{2}$ passive layer. For instance, for Ti spherical particles of $2 \mu \mathrm{m}$ in diameter with a surface oxide layer of $3 \mathrm{~nm}$ in thickness, the oxygen content can be around $3900 \mathrm{ppm}$ [35]. Hence, in order to produce Ti metal with oxygen content less than $1500 \mathrm{ppm}$ as required for $\mathrm{Ti}$ sponge, the particle size of $\mathrm{Ti}$ metal powder must be greater than 5.2 micrometers assuming the thickness of the passive oxide layer remains at $3 \mathrm{~nm}$. Thus, this process is deliberately designed to produce relatively coarse $\mathrm{TiO}_{2}$ with particle sizes in the range of 10 to 50 microns so that when it is reduced, it will retain the same relatively coarse particle size and form relatively coarse Ti metal powder in the end.

Third, for pigment production, iron is one of the detrimental impurities [36]. With a $\mathrm{Fe}_{2} \mathrm{O}_{3}$ content of 30 ppm, $\mathrm{TiO}_{2}$ will present a light yellow color. Usually 90 ppm of $\mathrm{Fe}_{2} \mathrm{O}_{3}$ is considered as a threshold value at which $\mathrm{Fe}_{2} \mathrm{O}_{3}$ affects the whiteness of A-type $\mathrm{TiO}_{2}$ [37]. However, iron content in Ti metal does not need to be so low. ASTM specification for general purpose Ti sponge requires Fe content only to be less than $1500 \mathrm{ppm}$, which is much easier to achieve. Consequently, a process as described above which is a lower cost process as compared to the chloride process for making pigment $\mathrm{TiO}_{2}$ can and should be used to prepare $\mathrm{TiO}_{2}$ for the purpose of producing Ti metal. 


\section{2 $\mathrm{Mg}$ reduction}

$\mathrm{Mg}$ is one of the reductants that can form more stable oxides than $\mathrm{TiO}_{2}$. Even though the reported results to date show that the ability of $\mathrm{Mg}$ for reduction is limited $[18,38]$ as compared to $\mathrm{Ca}, \mathrm{Mg}$ is selected for this work because of a number of factors including that the cost of $\mathrm{Mg}$ is significantly lower than that of $\mathrm{Ca}$, the potential reaction temperature is lower, and controllability of the reduction process of using $\mathrm{Mg}$ will be better than using $\mathrm{Ca}$. However, the challenge is how to reduce the oxygen content to a satisfactory level by using a Mg based process.

To improve the efficiency and effectiveness of the reduction of $\mathrm{TiO}_{2}$ using $\mathrm{Mg}$, previous work by the present authors [17] showed that the $\mathrm{Mg}$ reduction should be conducted in a hydrogen atmosphere using magnesium chloride salt as a medium. When the reaction is conducted in $\mathrm{H}_{2}, \mathrm{TiH}_{2}$ is formed. As pointed out in the earlier section on the design of the overall process, forming $\mathrm{TiH}_{2}$ powder as the product of the reduction reaction is viewed as being more advantageous than forming Ti metal powder with respect to both oxygen content and purity of the product.

In this work, the same general approach for reduction is adopted. Purified $\mathrm{TiO}_{2}$ was mixed with $\mathrm{Mg}$ metal and alkaline salt including $\mathrm{MgCl}_{2}$. The mixture was heated and held at various temperatures in $\mathrm{H}_{2}$ atmosphere. The reaction product included $\mathrm{TiH}_{2}$ and $\mathrm{MgO} . \mathrm{MgO}$ was leached using a dilute $\mathrm{HCl}$ solution. The objective of the process is to minimize oxygen content. The following descriptions of the results show the effects of hydrogen, salt, and temperature on the reduction. 
Additionally, magnesiothermic reduction generates a large amount of exothermic heat, which could lead to a system temperature as high as $1600{ }^{\circ} \mathrm{C}$ when the reduction is initiated [39]. Consequently, one of the goals of this work is to control the reaction at a relatively low temperature and with an acceptable reduction rate, avoiding any severe temperature spike.

\subsubsection{Effect of $\mathrm{MgCl}_{2}$-bearing salt}

In order to understand the effect of salt, TGA-DSC analysis techniques were used. Figure 5 presents the DSC curves during heating of a $\mathrm{TiO}_{2}$ mixture with $\mathrm{MgH}_{2}$ (compared to $\mathrm{Mg}$ metal, $\mathrm{MgH}_{2}$ powder is easier to grind to finer sizes) with and without $\mathrm{MgCl}_{2} / \mathrm{KCl}$ eutectic salt (molar ratio of $\mathrm{MgCl}_{2}$ to $\mathrm{KCl}$ was 2:3), which shows a significant difference with respect to the exothermic heat due to the reduction reaction. In the presence of salt, an exothermic peak at $538^{\circ} \mathrm{C}(\mathrm{c} 1)$ attributable to the reduction reaction was clearly visible. The reaction happened before the melting of $\mathrm{Mg}(\mathrm{d} 1$ and $\mathrm{d} 2)$. Furthermore, the peak that indicates the solidification of metallic $\mathrm{Mg}$ (e1 and e2) was notably smaller when the salt was added in the system, suggesting that there is little residual unreacted $\mathrm{Mg}$; in other words, the reaction was more complete when the salt was used. Thus, it appears that the initial reaction temperature of $\mathrm{Mg}$ reduction was lowered and the kinetic rate was improved when the salt with a lower melting point than $\mathrm{Mg}$ was used. 


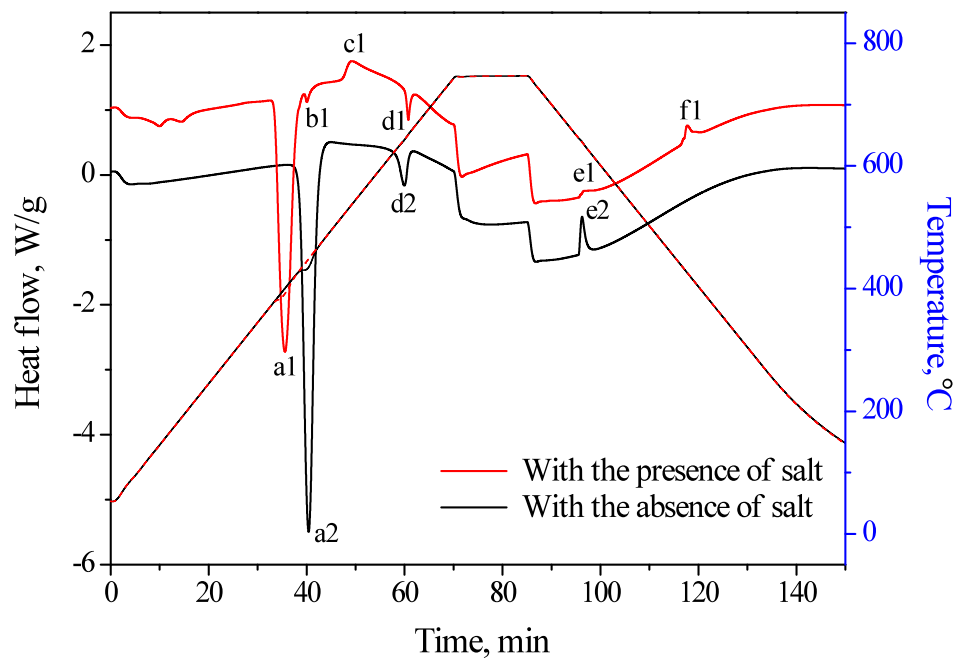

Fig. $5 \mathrm{DSC}$ curves when reducing $\mathrm{TiO}_{2}$ by $\mathrm{MgH}_{2}$ in the presence or absence of $\mathrm{MgCl}_{2} / \mathrm{KCl}$ eutectic salt. [red line: with the presence of salt; dark line: with the absence of salt; a1 and a2: dehydrogenation of $\mathrm{MgH}_{2} ; \mathrm{b} 1$ : melting of the salt; $\mathrm{c} 1$ : exothermic reduction; $\mathrm{d} 1$ and $\mathrm{d} 2$ : melting of $\mathrm{Mg}$ metal; e1 and e2: solidification of remaining $\mathrm{Mg}$ metal; f1: solidification of salt]

Furthermore, the TGA-DSC technique is also used to screen salt with different compositions. The DSC curves of salt mixtures with different ratios of $\mathrm{MgCl}_{2}: \mathrm{KCl}$ were compared in Fig. 6. The mixed salts of $\mathrm{MgCl}_{2}$ with $\mathrm{KCl}$ were considered because they generally possess lower eutectic temperatures. Figure 6 shows that the peak temperature positions for the exothermic reactions were not affected significantly by the compositions of the salts. However, the intensity of the exothermic reaction varied. The peak intensity grew stronger when the molar ratio changed from 1:0.25 to 1:0.5, followed by a gradual weakening until the ratio reached 1:4. The stronger the exothermic peak, the smaller the remaining quantity of $\mathrm{Mg}$, determined by the peak intensities for the solidification of remaining $\mathrm{Mg}$. 
Hence, it seems that the most suitable molar ratio of $\mathrm{MgCl}_{2}$ to $\mathrm{KCl}$ was 1:0.5 with respect to the kinetics of the reduction reaction.
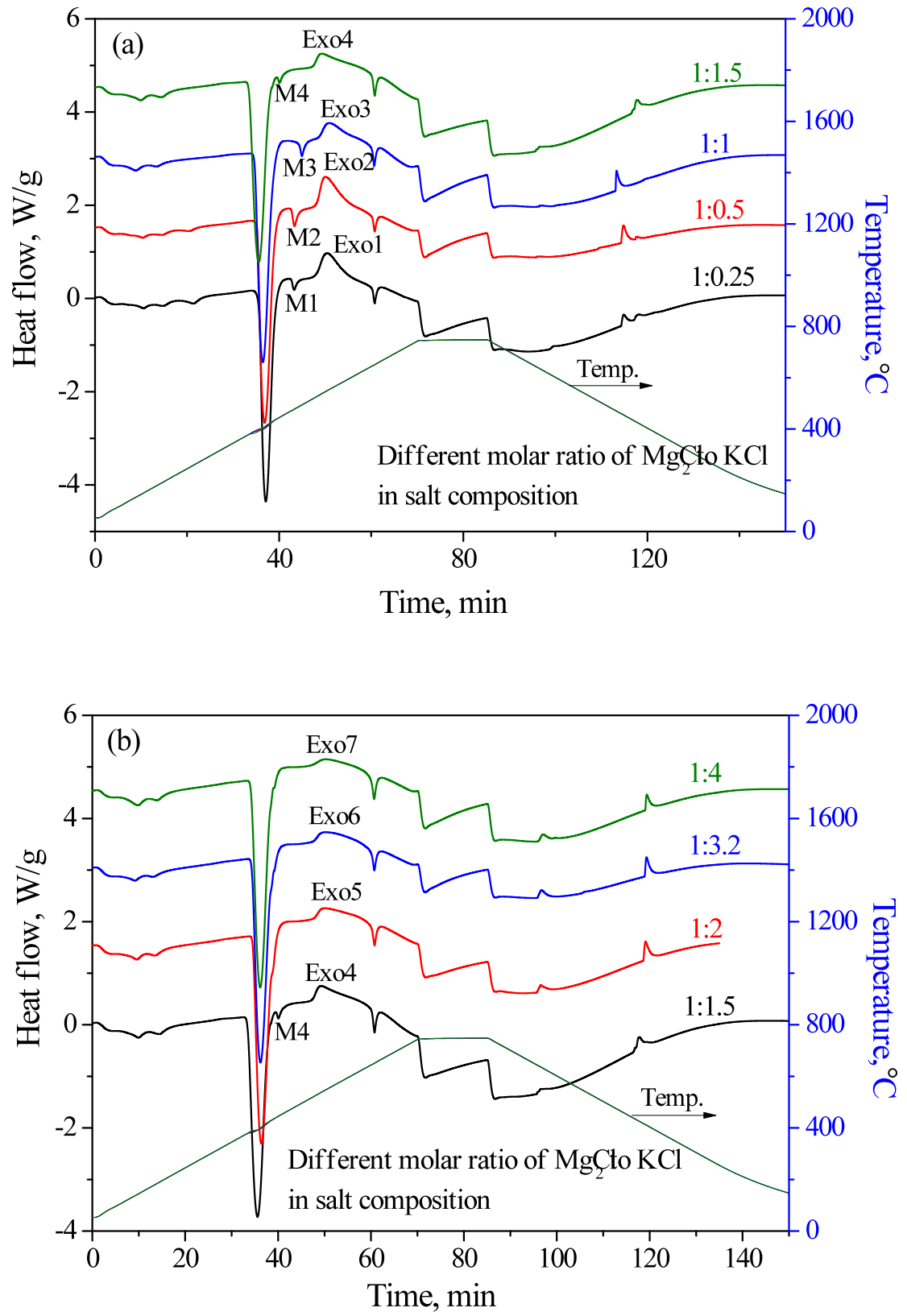

Fig. $6 \mathrm{DSC}$ curves when reducing $\mathrm{TiO}_{2}$ by $\mathrm{MgH}_{2}$ with the presence of eutectic salt with various compositions

The effects of the compositions of salts are also compared by measuring the oxygen 
content after reduction. The reduction was conducted by holding the sample for 6 hours at $750{ }^{\circ} \mathrm{C}$ in $\mathrm{H}_{2}$ atmosphere. The oxygen content in the reduced powder as measured using a LECO oxygen analyzer are shown in Fig. 7. Clearly, the compositions of salts affect not only the kinetic rate, but also the oxygen content after the reduction. The oxygen level in the reduced powder can be reduced to $1.5 \%$ when the $\mathrm{MgCl}_{2}: \mathrm{KCl}$ molar ratio is greater than $1: 0.5$ at $750{ }^{\circ} \mathrm{C}$.

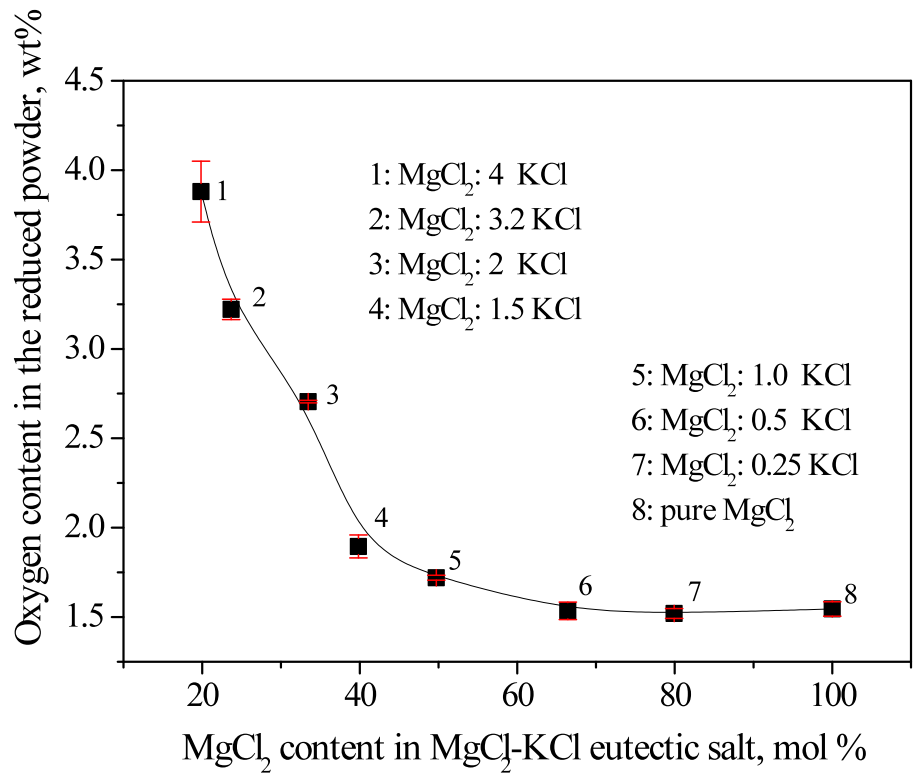

Fig. 7 Variation of reduction efficiency with the chemical composition of the eutectic salt

It should be noted here that although the positive effects of salt on the kinetics of the reduction of $\mathrm{TiO}_{2}$ by $\mathrm{Mg}$ is clear from the above the results, the fundamental mechanisms of the effects of salt on reduction is still not fully understood. Preliminary study has showed that the reduction of $\mathrm{TiO}_{2}$ by $\mathrm{Mg}$ can take place without the direct contact between $\mathrm{TiO}_{2}$ and $\mathrm{Mg}$. It suggests that the salt can facilitate the mass transfer of the reductant, thus enhance the kinetic rate of the reduction. However, a comprehensive discussion of this issue is beyond the scope of this article. 


\subsubsection{Effect of reduction temperature}

The DSC analysis showed that the reduction temperature with $\mathrm{MgCl}_{2}-\mathrm{KCl}$ eutectic salt as medium should be set higher than $550{ }^{\circ} \mathrm{C}$ which is the temperature at which the exothermic peak appears. The effect of temperature was further investigated by experiments at various temperatures, namely $550{ }^{\circ} \mathrm{C}, 590{ }^{\circ} \mathrm{C}, 630{ }^{\circ} \mathrm{C}, 680{ }^{\circ} \mathrm{C}, 750{ }^{\circ} \mathrm{C}$ and $800^{\circ} \mathrm{C}$. The temperatures were selected to cover the range of exothermic peaks and to be either higher or lower than the melting point of $\mathrm{Mg}$.

The effect of temperature is evaluated by measuring the titanium contents in the powder after $\mathrm{MgO}$ is leached, as shown in Fig. 8. It shows that Ti content increased dramatically with the elevation of the reduction temperature, indicating that a temperature higher than the peak point in the DSC curve is necessary to guarantee a relatively high degree of reduction.

Additionally, the $\mathrm{Mg}$ contents were found to be high in samples that were reduced at lower temperatures. This is attributed to the formation of magnesium titanate that is insoluble in the acid solutions.

Based on the above results, $750{ }^{\circ} \mathrm{C}$ was adopted as the optimum temperature for reducing $\mathrm{TiO}_{2}$ with $\mathrm{Mg}$. 


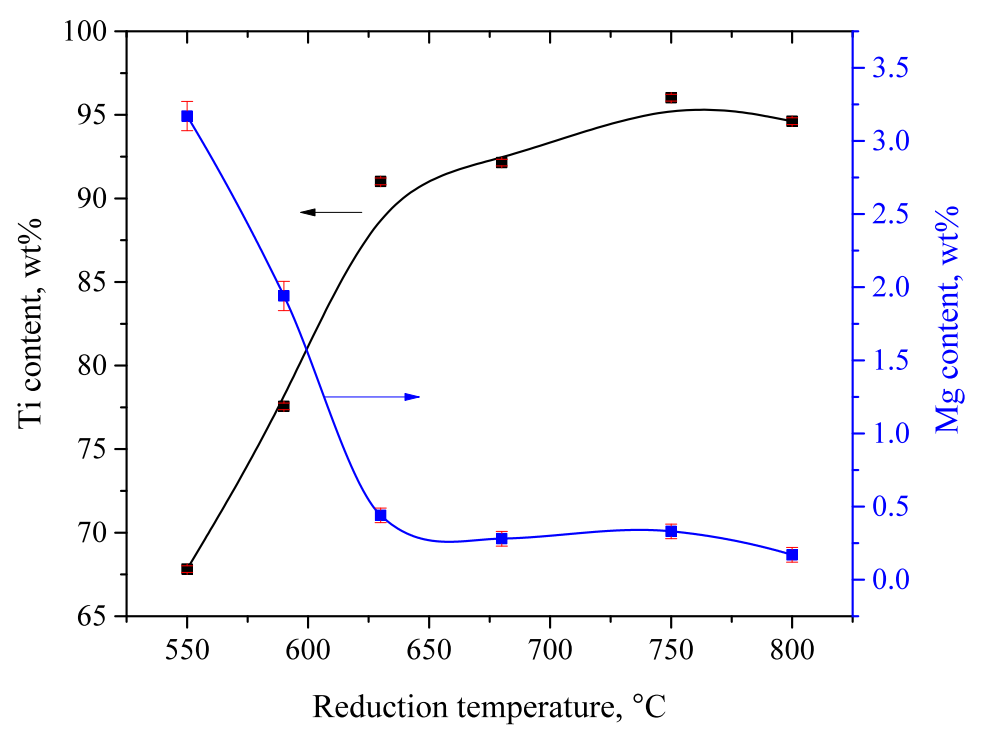

Fig. $8 \mathrm{Ti}$ and $\mathrm{Mg}$ contents in the leached powders reduced at various temperatures

(The mass ratio of $\mathrm{TiO}_{2}$ to salt was 1:0.5, and the excess coefficient of $\mathrm{Mg}$ was 1.5)

\subsubsection{Effect of hydrogen}

As mentioned earlier, the $\mathrm{Mg}$ reduction is conducted in hydrogen atmosphere in this work. The effect of hydrogen is shown in Table 6. It shows that the oxygen content of the product powder that was reduced in hydrogen atmosphere is significantly lower than that reduced in argon atmosphere. It can be shown that the thermodynamic equilibrium between $\mathrm{Ti}$ containing oxygen and $\mathrm{Mg}$ is different under hydrogen atmosphere than under inert atmosphere or vacuum, favoring the reduction of $\mathrm{TiO}_{2}$. However, further in-depth research is needed to elucidate the underlying thermodynamics, which is the subject of a parallel investigation by the present authors.

Furthermore, as described in the process design, the process is deliberately designed to form $\mathrm{TiH}_{2}$ instead of $\mathrm{Ti}$ metal after reduction because $\mathrm{TiH}_{2}$ is known to be impervious to 
oxygen as compared to $\mathrm{Ti}$ metal. This has strong practical implications for handling of powders after the reduction.

The remaining oxygen in the reduced product will need to be removed through a deoxygenation process using $\mathrm{Ca}$ which will be discussed in the next section. As mentioned earlier, one of the reasons that $\mathrm{Mg}$ was chosen as the redutant for this process is that it is less costly than Ca. Needless to say that the lower the oxygen content in the powder prior to the deoxygenation process, the less Ca will be needed, thus the lower the cost.

Table 6 Oxygen content of the powder after $\mathrm{Mg}$ reduction in $\mathrm{H}_{2}$ and $\mathrm{Ar}$ atmosphere*

\begin{tabular}{ccc}
\hline & $\mathrm{H}_{2}$ atmosphere & Ar atmosphere \\
\hline Oxygen content, $\mathrm{wt} \%$ & $1.37 \%$ & $2.90 \%$ \\
\hline * Other reduction parameters: the mass ratio of $\mathrm{TiO}_{2}$ to salt was $1: 0.5$, the excess coefficient \\
of $\mathrm{Mg}$ was 1.2 , and reduction temperature and time were $750{ }^{\circ} \mathrm{C}$ for 6 hours.
\end{tabular}

\subsubsection{Reduction of $\mathrm{TiO}_{2}$ by $\mathrm{Mg}$ and the production of porous $\mathrm{TiH}_{2}$}

Based on the understanding of the effects of key parameters above, the reduction of $\mathrm{TiO}_{2}$ is carried out as follows. Rutile particles with particle sizes in the range of 10-50 micrometer were used. The $\mathrm{TiO}_{2}$ particle were mixed with the same mass of salt (mole ratio of $\mathrm{MgCl}_{2}$ to $\mathrm{KCl}$ was 1:0.5) and 1.2 1.5 times of theoretical amount of $\mathrm{Mg}$ needed for reduction. The reduction was conducted at $750{ }^{\circ} \mathrm{C}$ in $\mathrm{H}_{2}$ atmosphere for 6 hours.

After reduction, the reduced powder was pulped by high-purity water first, and then leached by concentrated $\mathrm{HCl}$ using a peristaltic pump controlled dripping technique to 
remove $\mathrm{MgO}$ and unreacted $\mathrm{Mg}$ metal. The slurry was stirred for 30 minutes until the $\mathrm{pH}$ value of the leachate reached 3 to 4 . Finally, $\mathrm{TiH}_{2}$ intermediate was obtained after filtration, water washing, and drying. The phase composition of the product powder was determined by using XRD as shown in Fig.13 (D). The critical metal and interstitial impurity contents in $\mathrm{TiH}_{2}$ were analyzed using ICP as presented in Table 7. The morphology of $\mathrm{TiH}_{2}$ was irregular and large in size with a porous structure having a BET determined specific surface area of $3.46 \mathrm{~m}^{2} / \mathrm{g}$.

Table 7 Impurity contents in $\mathrm{TiH}_{2}$ intermediate

\begin{tabular}{cccccccccc}
\hline $\mathrm{Mg}$ & $\mathrm{Al}$ & $\mathrm{Fe}$ & $\mathrm{Si}$ & $\mathrm{Ca}$ & $\mathrm{Cr}$ & $\mathrm{V}$ & $\mathrm{Mn}$ & $\mathrm{O}$ & $\mathrm{C}$ \\
\hline 0.123 & 0.012 & 0.058 & 0.035 & 0.030 & 0.024 & 0.057 & 0.005 & 1.50 & 0.015 \\
\hline
\end{tabular}
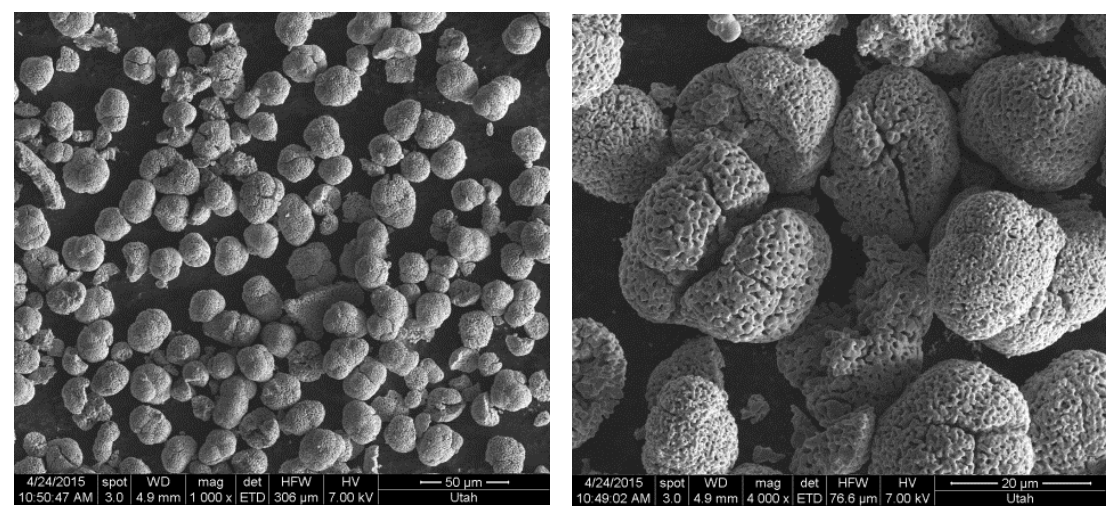

Fig.9 Morphology of the porous $\mathrm{TiH}_{2}$ produced by reducing coarse $\mathrm{TiO}_{2}$ by $\mathrm{Mg}$

\subsection{Heat treatment and de-oxygenation}

As indicated above, the oxygen content of the $\mathrm{TiH}_{2}$ powder after the reduction of $\mathrm{TiO}_{2}$ by $\mathrm{Mg}$ was over $1 \%$, which is too high for commercial $\mathrm{Ti}$. Therefore, further measures are 
needed to reduce oxygen content. First of all, the oxygen content of Ti powder is typically a function of the particle sizes, which is inversely proportionally to specific surface areas of the powder. Therefore, one of the measures to reduce the final oxygen content is to reduce the specific surface area of the $\mathrm{TiH}_{2}$ powder, which is the product of the reduction.

As shown earlier, the $\mathrm{TiH}_{2}$ powder was porous. The sizes of the pores range from 400 to $600 \mathrm{~nm}$. Consequently the specific surface area of the porous $\mathrm{TiH}_{2}$ is extremely large. To reduce the surface area, the porous $\mathrm{TiH}_{2}$ was heat treated in argon at $900{ }^{\circ} \mathrm{C}$ for 10 minutes (Fig. 10). $\mathrm{TiH}_{2}$ particles were also dehydrogenated at temperatures above $700{ }^{\circ} \mathrm{C}$. The volume of individual Ti particles shrank compared to original $\mathrm{TiH}_{2}$ particles. The sizes are still as large as around $20 \mu \mathrm{m}$. The BET values of the powders were significantly decreased, from $3.46 \mathrm{~m}^{2} / \mathrm{g}$ to $0.09 \mathrm{~m}^{2} / \mathrm{g}$. The cross section of the Ti particles is shown in Fig. 11, illustrating that the porosity was eliminated after heat treatment. The high relative density of the powder was measured using a Pycnometer as $98.2 \%$ of the theoretical density of pure Ti. The oxygen content of the Ti particles after the heat treatment was measured at $1.52 \mathrm{wt} \%$, which is similar to that of the $\mathrm{TiH}_{2}$ powder before the heat treatment.

To further reduce the oxygen content of the Ti particles, a de-oxygenation step was applied to the powder after the heat treatment. As mentioned earlier, Ca de-oxygenation is widely reported in literatures. However, in order to avoid using high temperatures above 900 ${ }^{\circ} \mathrm{C}$, a new low temperature molten salt (LTMS) process was developed and used in this work [22]. In this process, de-oxygenation was carried out by mixing the powder with Ca metal and anhydrous $\mathrm{CaCl}_{2}-\mathrm{KCl}$ mixed salt, followed by treatment in argon at around $750-800{ }^{\circ} \mathrm{C}$ 
for 12 hours. After de-oxygenation, the remnant $\mathrm{Ca}, \mathrm{CaO}$ (byproduct), and salt were leached by using an $\mathrm{HCl}$ solution and washed using high-purity water.

The morphology of final Ti metal powder is shown in Fig. 12, which inherited the shape of heat-treated Ti particles. The oxygen content of the powder was decreased drastically from $1.5 \%$ to $0.11 \%$ (Table 8 ). The chemical composition of the Ti powder produced by using this process is compared with the ASTM standard specifications for Ti sponge as shown in Table 8. Clearly that the Ti powder produced using the process described in this paper meets the requirements of the ASTM standard.
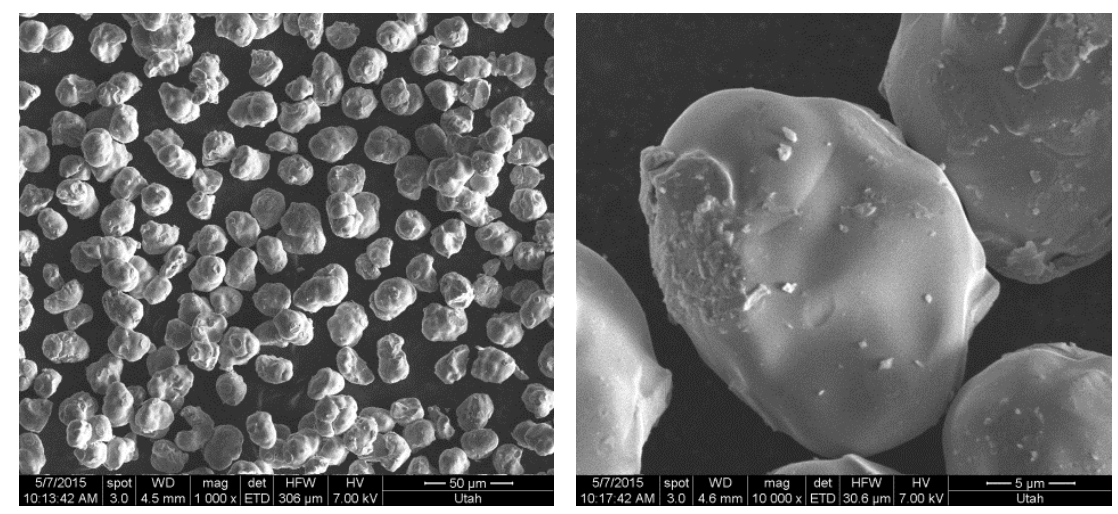

Fig. 10 Morphology of Ti particles obtained by heat treating porous $\mathrm{TiH}_{2}$

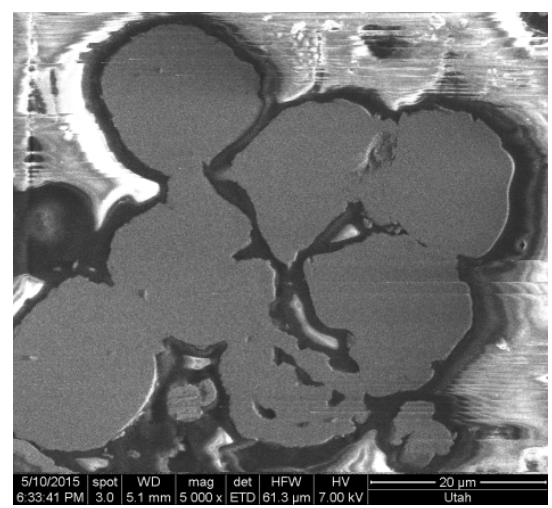

Fig. 11 Cross section of Ti particles obtained by heat treating porous $\mathrm{TiH}_{2}$ 

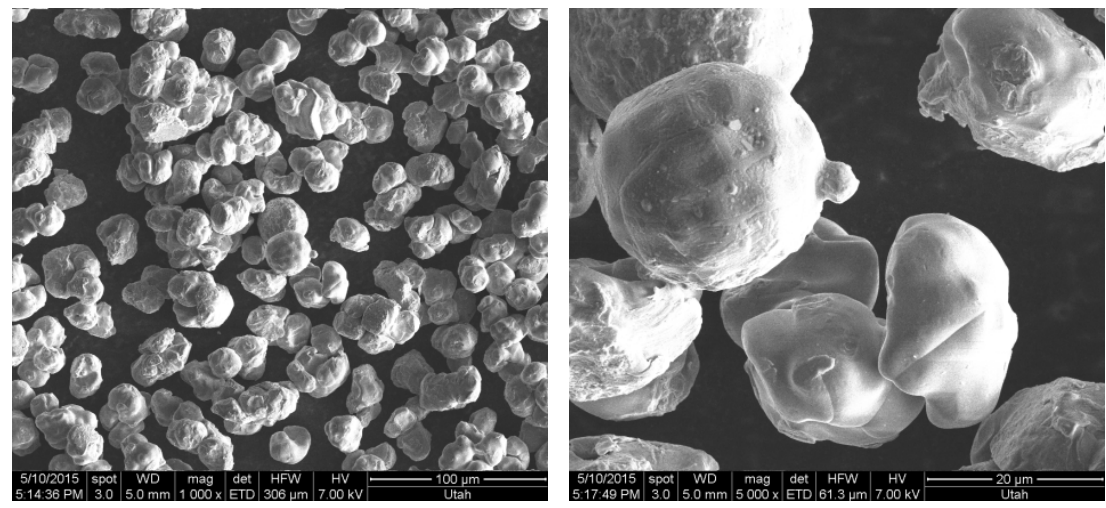

Fig. 12 Morphology of final Ti metal powder after de-oxygenation

Table 8 Chemical composition of final Ti metal powder produced by this process, wt $\%$

\begin{tabular}{cccccccccccc}
\hline & $\mathrm{Mg}$ & $\mathrm{Al}$ & $\mathrm{Fe}$ & $\mathrm{Si}$ & $\mathrm{Cl}$ & Water & $\mathrm{O}$ & $\mathrm{N}$ & $\mathrm{C}$ & $\mathrm{H}$ \\
\hline This work & 0.067 & 0.021 & 0.044 & 0.036 & 0.001 & $/$ & 0.11 & 0.019 & 0.03 & 0.028 \\
& & & & & & & & & & \\
ASTM-B299-13 & & & & & & & & & & \\
$(\mathrm{GP})$ & 0.5 & 0.05 & 0.15 & 0.04 & 0.2 & 0.02 & 0.15 & 0.02 & 0.03 & 0.03 \\
\hline
\end{tabular}

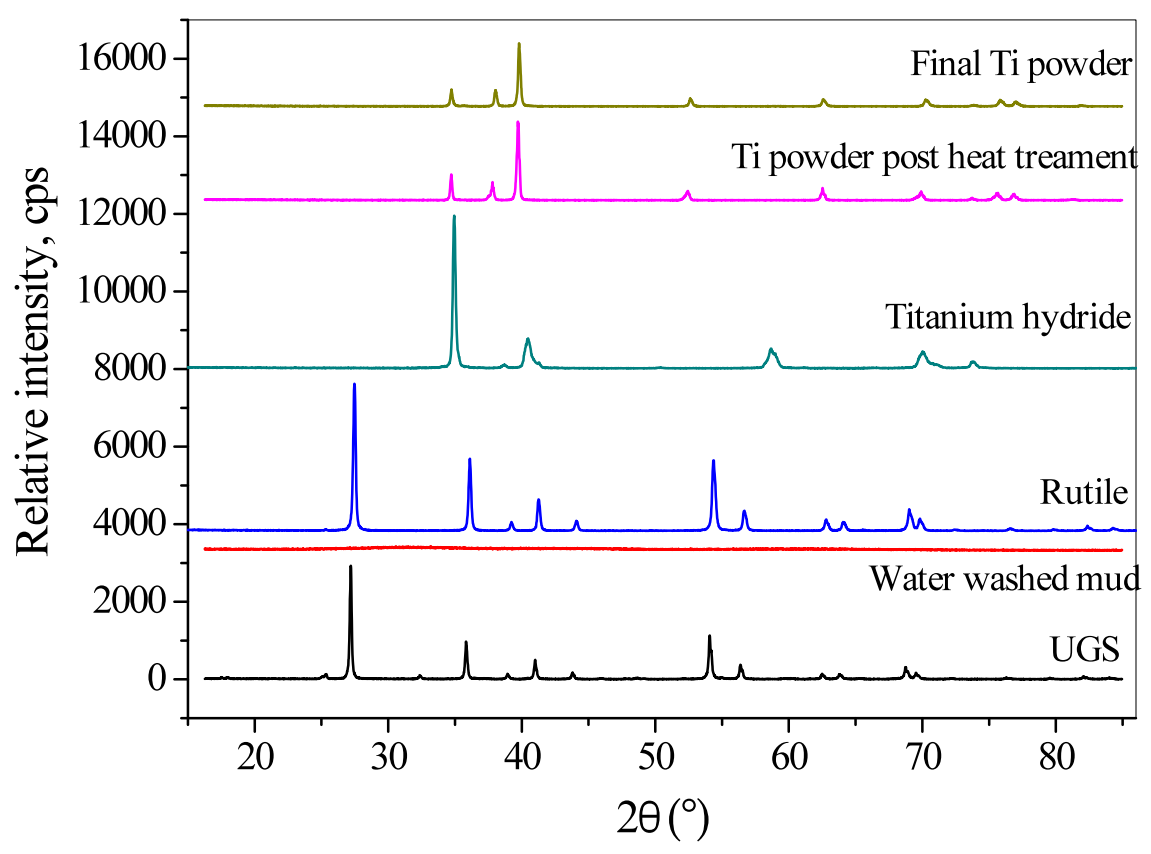



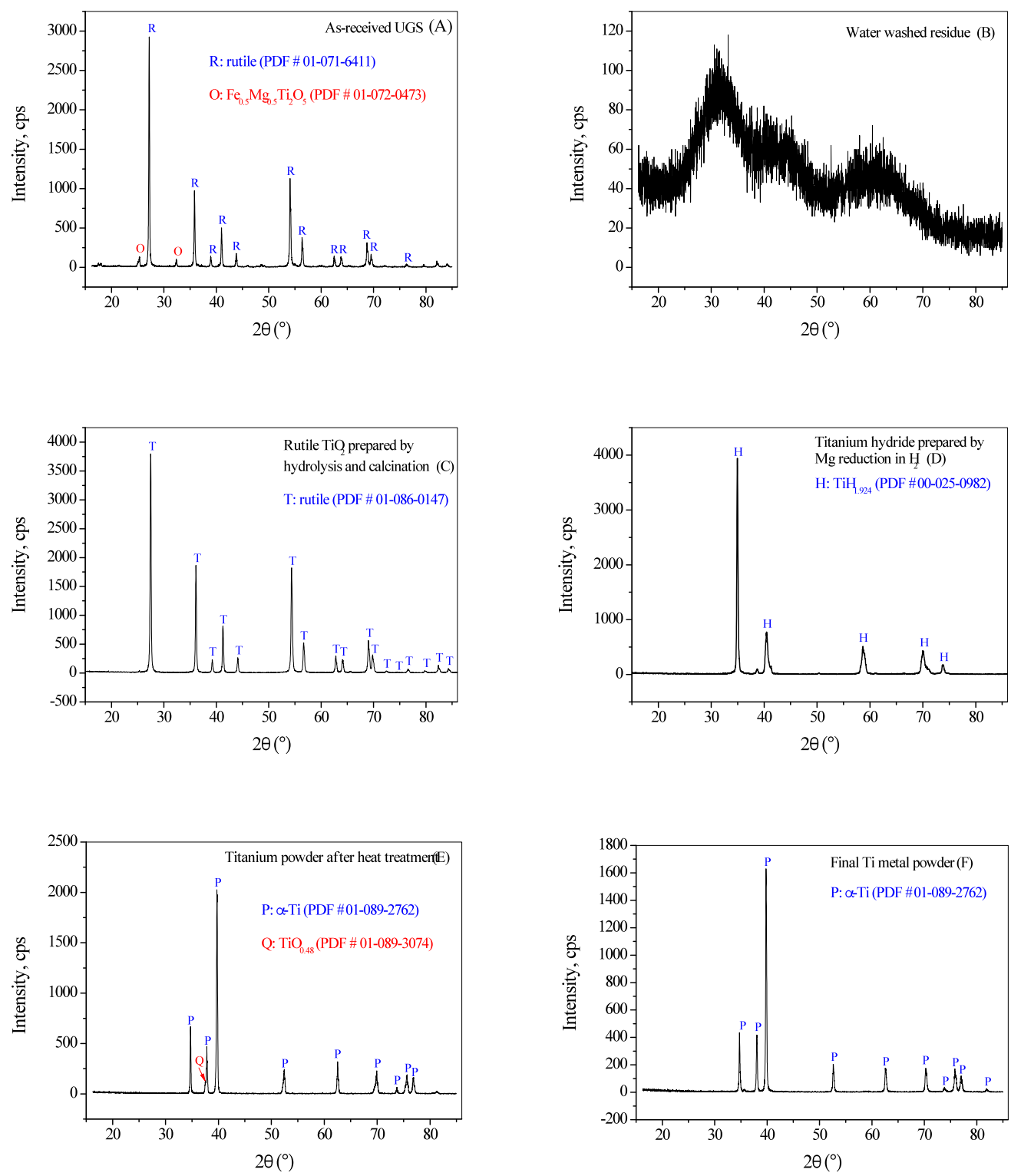

Fig. 13 XRD patterns for the original UGS (A), intermediates (B, C,D and E) and final product $(\mathrm{F})$

\section{Summary}

A new chemical pathway for producing high purity low oxygen Ti metal powder directly from UGS is demonstrated. The new process is based on integrating synergistically a series of unit processes that are designed to accomplish the tasks of purification, reduction, and 
deoxygenation sequentially. The overall process includes three key steps: production of purified $\mathrm{TiO}_{2}, \mathrm{Mg}$ reduction of $\mathrm{TiO}_{2}$ in hydrogen atmosphere, and de-oxygenation of $\mathrm{Ti}$ powder using Ca. A key step is the hydrolysis process that produces relatively coarse $\mathrm{TiO}_{2}$ with controlled sizes and morphologies that allows $\mathrm{Mg}$ reduction in the presence of hydrogen to form porous $\mathrm{TiH}_{2}$. The de-oxygenation process using $\mathrm{Ca}$ enables the production of powder with less than $0.15 \%$ oxygen. The purity of $\mathrm{Ti}$, or the impurity content of the powder produced using this process, meets the specifications by ASTM for Ti sponge.

\section{Acknowledgement}

This work was financially supported by the US Department of Energy (DOE), Advanced Research Projects Agency - Energy (ARPA-E), under contract number DE-AR0000420.

\section{Reference}

[1] J. Gambogi, S.J. Gerdemann, Titanium Metal: Extraction to Application, Review of Extraction, Processing, Properties \& Applications of Reactive Metals (2013) 175-210.

[2] W. Mo, Titanium metallurgy, Metallurgical Industry Press1998.

[3] G.Z. Chen, D.J. Fray, T.W. Farthing, Direct electrochemical reduction of titanium dioxide to titanium in molten calcium chloride, Nature 407 (2000) 361-364.

[4] G.S. Hartman AD, Hansen JS, Producing lower-cost titanium for automotive applications, JOM 50 (1998) 16-19. 
[5] B. Xu, B. Yang, J. Jia, D. Liu, H. Xiong, Y. Deng, Behavior of calcium chloride in reduction process of titanium dioxide by calcium vapor, J. Alloys Compd. 576 (2013) 208-214.

[6] H. Nersisyan, H. Won, C. Won, A. Jo, J. Kim, Direct magnesiothermic reduction of titanium dioxide to titanium powder through combustion synthesis, Chem. Eng. J. 235 (2014) 67-74.

[7] H. Zheng, H. Ito, T.H. Okabe, Production of titanium powder by the calciothermic reduction of titanium concentrates or ore using the preform reduction process, Mater. Trans. 48 (2007) 2244-2251.

[8] P.P. Alexander, Production of titanium hydride, US 2427338, 1947.

[9] T.H. Okabe, T. Oda, Y. Mitsuda, Titanium powder production by preform reduction process (PRP), J. Alloys Compd. 364 (2004) 156-163.

[10] T. Kikuchi, M. Yoshida, S. Matsuura, S. Natsui, E. Tsuji, H. Habazaki, R.O. Suzuki, Rapid reduction of titanium dioxide nano-particles by reduction with a calcium reductant, J. Phys. Chem. Solids 75 (2014) 1041-1048.

[11] T. Abiko, I. Park, T.H. Okabe, Reduction of titanium oxide in molten salt medium, 10th World Conference on Titanium, Hamburg, Germany, 2003.

[12] M.A. Hunter, Metallic titanium, JACS 32 (1910) 330-336.

[13] G. Crowley, A new process for titanium extraction and production promises to cut costs and expand applications, Advanced materials \& processes (2003) 25-27.

[14] H.S. Dombrowski, Production of high-purity, ductile titanium powder, US 2984560 A, 1961. 
[15] J.D. Leland, Aerosol reduction process for metal halides, US 5460642 A, 1995.

[16] R. Kohli, Production of titanium from ilmenite: a review, Lawrence Berkeley Lab., CA (USA), 1981.

[17] Z.Z. Fang, S. Middlemas, J. Guo, P. Fan, A new, energy-efficient chemical pathway for extracting Ti Metal from Ti minerals, JACS 135 (2013) 18248-18251.

[18] M.S.R. Bolívar, I.B. Friedrich, M. Recycling, Synthesis of titanium via magnesiothermic reduction of TiO2 (Pigment), Proceedings of EMC (2009) 1-17.

[19] J.M. Oh, B.K. Lee, C.Y. Suh, S.W. Cho, J.W. Lim, Deoxidation of Ti powder and preparation of $\mathrm{Ti}$ ingot with low oxygen concentration, Mater. Trans. 53 (2012) 1075-1077.

[20] R.O. Suzuki, M. Aizawa, K. Ono, Calcium-deoxidation of niobium and titanium in Ca-saturated $\mathrm{CaCl}_{2}$ molten salt, J. Alloys Compd. 288 (1999) 173-182.

[21] J.M. Oh, K.M. Roh, B.K. Lee, C.Y. Suh, W. Kim, H. Kwon, J.W. Lim, Preparation of low oxygen content alloy powder from $\mathrm{Ti}$ binary alloy scrap by hydrogenation-dehydrogenation and deoxidation process, J. Alloys Compd. 593 (2014) 61-66.

[22] Z.Z. Fang, X. Yang, P. Sun, Y. Zhang, A novel method for production of low cost titanium and titanium alloy powders with controlled size and morphology, US PCT/US15/30669, 2015.

[23] F.C. Michel Gueguin, Chemistry and mineralogy of titanium-rich slags. Part I-Hemo-ilmenite, sulphate, and upgtaded titania slags, Mineral Processing \& Extractive Metall. Rev. 28 (2007) 1-58. 
[24] W. Zhang, Z. Zhu, C.Y. Cheng, A literature review of titanium metallurgical processes, Hydrometallurgy 108 (2011) 177-188.

[25] S.A. Berkovich, Recovery of titanium dioxide from ores, US 3903239 A, 1975.

[26] S. Middlemas, Z.Z. Fang, P. Fan, A new method for production of titanium dioxide pigment, Hydrometallurgy 131 (2013) 107-113.

[27] D. Kemperman, Metallurgical processing of zinc bearing residues, (2010).

[28] Y. Ishikawa, Catalyst for generating hydrogen, method of generating hydrogen and apparatus for generating hydrogen, US 8845998 B2, 2014.

[29] T. Xue, L. Wang, T. Qi, J. Chu, J. Qu, C. Liu, Decomposition kinetics of titanium slag in sodium hydroxide system, Hydrometallurgy 95 (2009) 22-27.

[30] T. Xue, Production of Titanium Dioxide by Decomposition of Titanium Slag with Molten Sodium Hydroxide, Dalian University of Technology, (2009).

[31] S.C. Middlemas, Energy-conscious production of titania and titanium powders from slag, University of Utah, (2014).

[32] A. Bouzoubaa, A. Markovits, M. Calatayud, C. Minot, Comparison of the reduction of metal oxide surfaces: $\mathrm{TiO}_{2}$-anatase, $\mathrm{TiO}_{2}$-rutile and $\mathrm{SnO}_{2}$-rutile, Surf. Sci. 583 (2005) 107-117.

[33] A.S. Adkins, Spacer/extender for titanium dioxide in pigment systems for coatings, US 5171631 A, 1992.

[34] DuPont, Ti-Pure ${ }^{\circledR}$ Titanium Dioxide for Coatings.

[35] I. Chang, Y. Zhao, Advances in powder metallurgy: Properties, processing and applications, Elsevier 2013. 
[36] Q. Gao, X. Wu, Y. Fan, The effect of iron ions on the anatase-rutile phase transformation of titania $\left(\mathrm{TiO}_{2}\right)$ in mica-titania pigments, Dyes and Pigments 95 (2012) 96-101.

[37] http://www.chinabaike.com/z/keji/ck/543375.html.

[38] T.A. Henrie, H. Dolezal, E.K. Kleespies, Magnesium reduction of titanium oxides in a hydrogen atmosphere, US 3140170 A, 1964.

[39] C. Won, H. Nersisyan, H. Won, Titanium powder prepared by a rapid exothermic reaction, Chem. Eng. J. 157 (2010) 270-275. 